\title{
Evaluation and long-term outcomes of the different modalities used in colonic endoscopic mucosal resection
}

\author{
Asimina Gaglia, Sanchoy Sarkar \\ Royal Liverpool University Hospital, Liverpool, UK
}

\begin{abstract}
Endoscopic mucosal resection (EMR) has been used in western countries to remove colonic polyps for at least the last two decades. Significant experience has been accumulated and the efficacy of the method has recently been evaluated in a large meta-analysis. A number of variations to modify the technique, including knife-assisted, cap-assisted, ligation devices, and underwater EMR, have been developed in an attempt to improve outcomes. However, to date there are only limited data comparing these techniques or demonstrating the superiority of any one of them. This article reviews the current evidence on the efficacy of each of these modified techniques.
\end{abstract}

Keywords Endoscopic mucosal resection, colorectal polyps, endoscopic mucosal resectionprecutting

Ann Gastroenterol 2017; 30 (1): 1-7

\section{Introduction}

Endoscopic mucosal resection (EMR) is a well-defined technique for the removal of precancerous lesions. It involves submucosal injection of fluid underneath a lesion, which lifts it away from the muscular layer, facilitates easier snaring of flat or sessile lesions, reduces the risk of thermal transmural trauma, and identifies lesions with submucosal invasion or scarring, probably not amenable to endoscopic removal [1].

Several studies and meta-analyses in recent years have addressed the efficacy of EMR in treating large polyps within the colorectum, by assessing the recurrence rate, the number of follow-up endoscopic procedures needed to treat the residual lesion, the need for surgery after EMR, and the complication rates $[2,3]$. The EMR recurrence rate has been reported to be as high as $45 \%$ [4]. Many factors that contribute to this are discussed in this article, but one significant issue is that a piecemeal dissection is required for lesions greater than $20 \mathrm{~mm}$. In contrast, the technique of endoscopic submucosal dissection (ESD) for lesions provides en bloc specimens, which facilitate the accurate histopathological assessment of submucosal invasion, and has a significantly lower recurrence

Department of Gastroenterology, Royal Liverpool University Hospital, Liverpool, UK

Conflict of Interest: None

Correspondence to: Dr Asimina Gaglia, Consultant Gastroenterologist, Prescot Street, L7 8XP, Liverpool, Merseyside, UK, Tel.: +44 74290

12348, e-mail: asimina.gaglia@rlbuht.nhs.uk

Received 31 March 2016; accepted 4 July 2016;

published online 4 November 2016

DOI: https://doi.org/10.20524/aog.2016.0104 rate. However, ESD also suffers from some disadvantages compared to EMR: it is less accessible; it is significantly more time-consuming; it has higher complication rates; it is more expensive; and a long learning curve with prolonged training is required to master the technique, even for highly skilled endoscopists.

EMR has been an established technique for the last 25 years and the literature has recently provided high quality metaanalyses and data from prospective studies on its efficacy. Over this period, there have been modifications in the technique in an attempt to improve the outcomes of this procedure. However, comparative studies of the various modified techniques are lacking. This article reviews the variations and modified techniques of performing EMR, highlighting the differences and merits of each technique based on the current available literature.

\section{Indications for EMR and ESD}

The recent Japanese guidelines have set indications for both EMR and ESD (Tables 1 and 2) and have highlighted the need for endoscopic assessment of the lesion prior to resection to identify carcinomas and to assess the submucosal invasion depth [5]. ESD is an absolute indication for IIc or IIa+IIc lesions larger than $2 \mathrm{~cm}$. In addition, it is indicated for lateral spreading tumors of non-granular type (LST-NG), larger than $2 \mathrm{~cm}$, that may harbor superficial multifocal submucosal invasion in 30-56\% of cases [6] (Fig. 1).

These indications are led by the need for the above lesions to be removed en bloc, because of their high risk of harboring submucosal invasion. The higher incidence of submucosal fibrosis or submucosal invasion in these lesions could impede 
the EMR procedure, as it might lead to inadequate lifting of the lesion after the submucosal fluid injection (non-lifting

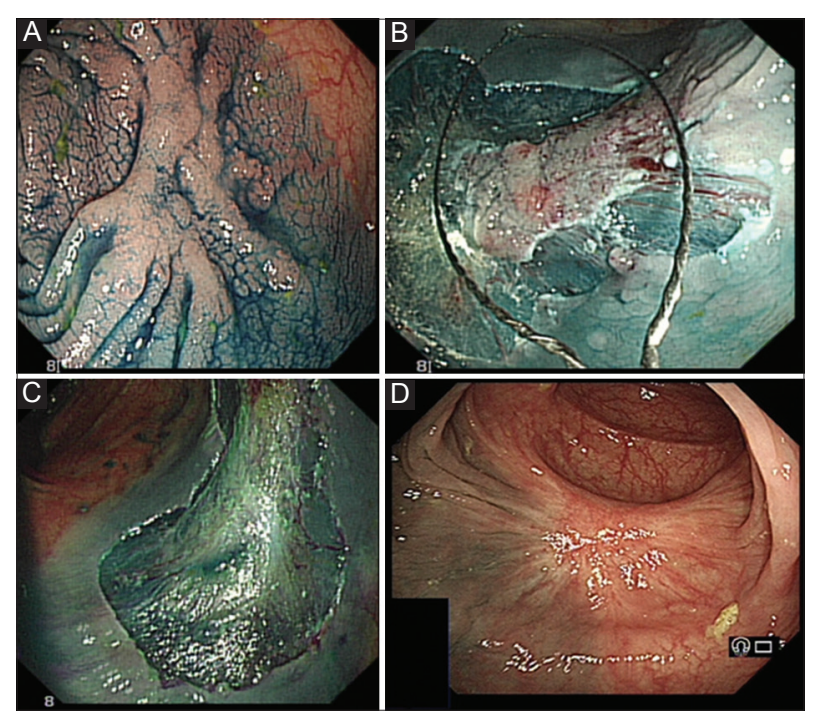

Figure 1 Case 1: EMR of LST-NG in the transverse colon. (A) LST-NGtransverse colon; (B) small stiff snare to deal with central area; (C) final results; (D) 3 months post EMR

$E M R$, endoscopic mucosal resection; LST-NG, lateral spreading tumors of non-granular type

Table 1 Indications for endoscopic mucosal dissection for colorectal tumors (Japanese guidelines)

Lesions for which endoscopic en bloc resection is required

\begin{tabular}{l} 
1. Lesions for which en bloc resection with EMR is difficult to apply \\
- LST-NG \\
- Lesions showing a V1-type pit pattern \\
- Carcinomas with shallow T1 (submucosal) invasion \\
- Large depressed-type tumors \\
- Large protruded-type lesions suspected to be carcinoma \\
2. Mucosal tumors with submucosal fibrosis \\
3. Sporadic localized tumors in conditions of chronic inflammation \\
such as ulcerative colitis \\
4. Local residual or recurrent early carcinomas after endoscopic \\
resection \\
\hline EMR, endoscopic mucosal resection; LST-NG, lateral spreading tumors of \\
non-granular type
\end{tabular}

sign) [2]. Additionally, piecemeal EMR may make it difficult to evaluate precisely the invasion depth and the free margins of carcinomas with less than $1000 \mu \mathrm{m}$ submucosal invasion depth (pT1a). Accurate histopathological evaluation is essential in these cases, which carry a low metastatic risk (1.5-1.9\%) in the colon and $4.2-4.5 \%$ in the rectum) and only endoscopic resection can be adequate, to prevent unnecessary surgery [7].

In the vast majority of cases referred for EMR (>90\%) within the western world submucosal invasion/malignancy is not an important factor and therefore EMR can be used safely as the preferred technique [8]. Even for lateral spreading tumors of granular type (LST-G) $>2 \mathrm{~cm}$, piecemeal EMR is an acceptable technique in the eastern world, provided that the largest nodule that may contain carcinoma will be removed en bloc and the rest of the lesion piecemeal (planned EMR) [5] (Figs. 2 and 3).

The assessment for submucosal invasion is carried out by ordinary observation, looking for surface unevenness, the presence of depression and fold convergence, by magnifying observation (pit pattern diagnosis) using dye spraying (indigo carmine, crystal violet, etc.) and image-enhancement technology (narrow-band imaging, blue-laser imaging) to assess fine surface structures and microvessels. Deep depression, an expansive appearance, a submucosal tumor-like margin or defective extension predict deep submucosal invasion in 70$80 \%$ of cases, which indicates direct referral for surgery.

The accuracy rate of discrimination between adenoma and carcinoma is between $70-90 \%$ using pit pattern observation or narrow-band imaging. If the $\mathrm{V}$ pit pattern is observed in a lesion with dye spraying and magnifying observation, the diagnostic accuracy of deep submucosal invasion is $90 \%$ [5].

\section{Long-term outcomes of standard EMR}

\section{Recurrence rate}

The recurrence rate following EMR is between $15-45 \%$. Large series, however, suggest that a more realistic value is around $15-18 \%$ [9]. The recurrence if seen at follow-up endoscopy is $91 \%$ at 6 months and $98 \%$ at 12 months. Consequently, follow-up protocols for lesions vary with first follow up at 3-6 months and another at 12 months, as studies

Table 2 Indications for colorectal ESD and EMR at National Cancer Centre Hospital in Japan

Non invasive patterns should be diagnosed by chromo magnification colonoscopy

\begin{tabular}{lllll}
\hline Tumor size (mm) & $<10$ & $10-20$ & $20-30$ & $>30$ \\
\hline 0-IIa, IIc, IIa+IIc (LST-NG) & EMR & EMR & ESD candidate & ESD candidate \\
0-Is+IIa (LST-G) & EMR & EMR & EMR & Possible ESD candidate \\
0-Is (villous) & EMR & EMR & EMR & Possible ESD candidate \\
Intramucosal tumor with non-lifting sign & EMR & EMR/ESD & Possible ESD candidate & Possible ESD candidate \\
Rectal carcinoid tumor & ESMR-L & ESD/Surgery & Surgery & Surgery \\
\hline
\end{tabular}

ESD, endoscopic submucosal dissection; EMR, endoscopic mucosal resection; LST-NG, lateral spreading tumors of non-granular type; ESMR-L, endoscopic submucosal resection with a ligation device 

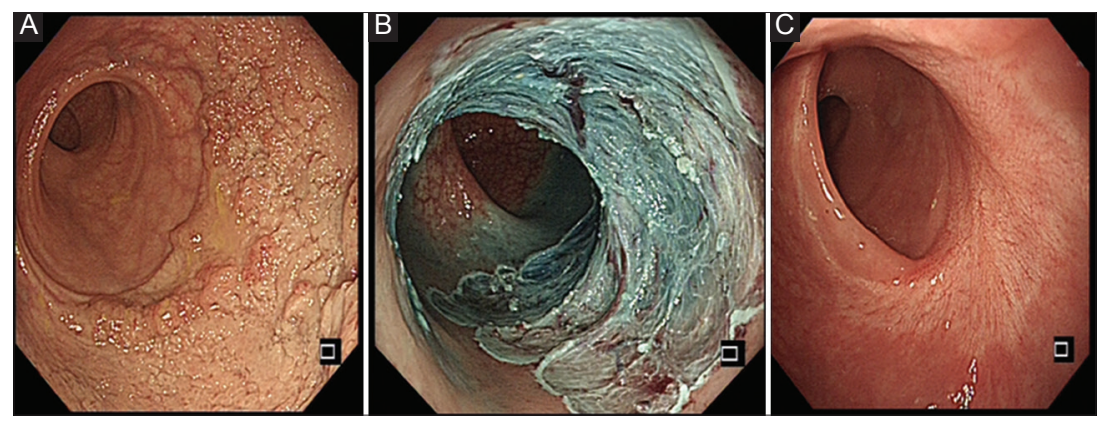

Figure 2 Case 2: EMR of LST-G. (A) $80 \mathrm{~mm}$ rectal LST-G; (B) Post-EMR; (C) At 3 months post EMR EMR, endoscopic mucosal resection; LST-G, lateral spreading tumors of granular type

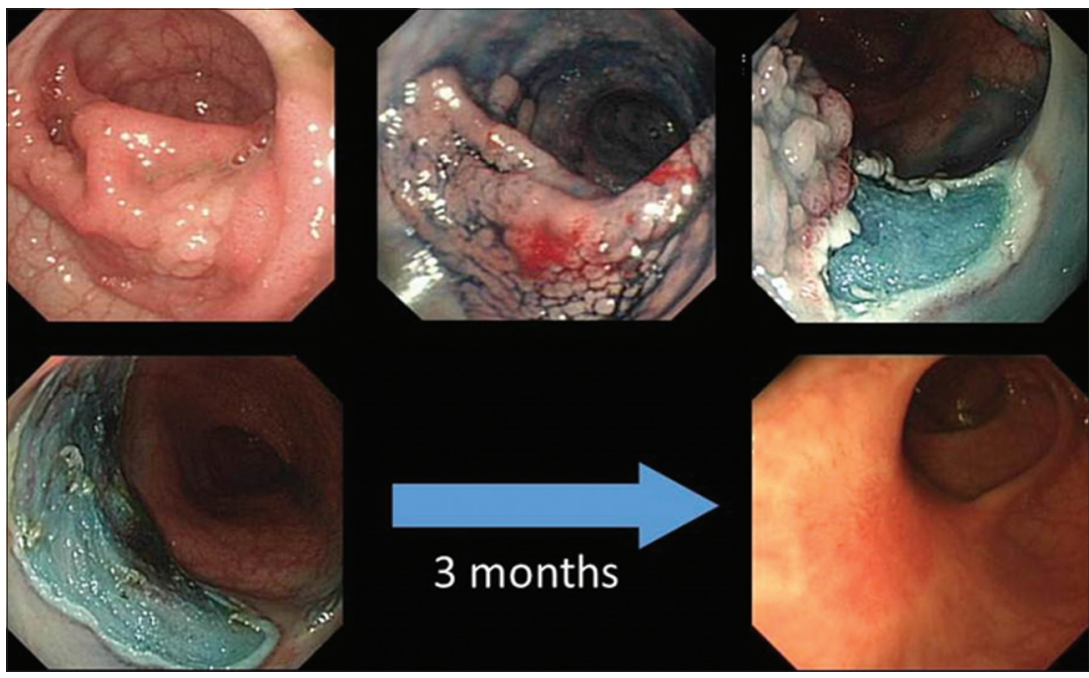

Figure 3 Case 3: EMR of LST-G

$E M R$, endoscopic mucosal resection; LST-G, lateral spreading tumors of granular type

have highlighted that recurrence can occur after a normal initial follow-up endoscopy in up to $12 \%$ of cases $[3,10]$.

The main predictors for recurrence have been shown to be piecemeal resection and large polyp size. A lesion size of greater than $20 \mathrm{~mm}$ has been shown to be significant (unsurprisingly, as piecemeal resection is required) [11]. One study has shown that if the lesion is $40 \mathrm{~mm}$ or more, there is a greater than 8-fold increase in the incidence of recurrence [9]. Of these recurrences, $91.4-93 \%$ are treated successfully after a mean number of 1.2 endoscopic treatments with either argon plasma coagulation (APC) or EMR [3,9]. There is conflicting evidence regarding the effectiveness of APC on recurrence. The reason is that whilst some meta-analyses have not identified this as a significant factor, other studies have shown a greater than 2-fold effect. The issues include the fact that many studies have not identified the use or non-use of APC within the procedure, and the context, i.e., use when clearance could not be attained or in the context of prophylaxis when clearance was achieved [12-15]. Prospective randomized trials are needed in this area. Other factors that have been identified include proximity to colonic folds and intraprocedural bleeds.

Other modalities used to reduce the recurrence rate or to treat recurrent adenomas are endoscopic mucosal ablation
(EMA) and the hot avulsion (HA) technique, which are also rescue treatments for fibrotic recurrent adenomas. EMA, a novel technique for the eradication of recurrent polyps with extensive submucosal scarring, combines submucosal fluid injection with high power APC. The submucosal injection provides a safety cushion that protects the muscularis propria, as high power APC needs to be applied for the eradication of extensively scarred residual polyps. In a pilot study, EMA as a "rescue" treatment successfully eradicated $82 \%$ of fibrotic recurrent polyps [16].

$\mathrm{HA}$ is a new variation of the hot biopsy (HB) that is used to eradicate residual or recurrent fibrotic adenomatous tissue, especially after snare polypectomy has failed. HB forceps are used to grasp neoplastic tissue with slight traction away from the polyp base while current is applied. The main difference between $\mathrm{HA}$ and $\mathrm{HB}$ is that $\mathrm{HB}$ uses forced coagulation current, which can result in transmural injury, while in HA ENDOCUT I or soft coagulation current is used. Studies have shown lower recurrence rates when macroscopically visible residual adenoma, non-amenable to snare resection, is treated with HA compared to APC (10\% vs. 59.3\%) [17]. It is also very promising in eradicating fibrotic recurrent polyps, with a success rate of up to $100 \%$ in small case series $[18,19]$. 


\section{Complication rates}

Delayed bleeding rates have been reported to be $1.6 \%$, $1.15-1.7 \%$, and $0.7-2.2 \%$ for polypectomy, EMR, and ESD, respectively $[20,21]$. In low-volume centers, delayed bleeding rates for large lesions have been reported to be up to $25 \%$, highlighting the need for tertiary referral.

In recent large studies, the rate of clinically significant bleeding post EMR for lesions $>20 \mathrm{~mm}$ is $5-7 \%$ [22-24]. Risk factors for post-EMR bleeding are lesions $>30 \mathrm{~mm}$ (odds ratio [OR] 2.5, 95\% CI 1.5-4.2), proximal colon location (OR 2.3, 95\% CI 1.4-4.0), or any major comorbidity at procedure (OR $1.5,95 \%$ CI $0.9-2.6$ ), while the use of epinephrine injection in the EMR solution (OR 0.57, 95\% CI 0.32-1.0), may modestly reduce post-EMR bleeding [25]. The use of aspirin during large EMRs has been evaluated in only two studies. An observational study with 302 lesions found an OR of 6.3, but a prospective multicenter study with 1172 lesions found no significant association $[23,26]$.

In $55 \%$ of cases of post-EMR bleeding, the bleeding stops spontaneously, whereas the rest will need endoscopic treatment and $1 \%$ will need primary embolization or surgery [28]. The prophylactic use of clips has been evaluated, and, although it seems to decrease the delayed bleeding rate, it is not cost-effective [27]. An individualized approach in cases with high risk for delayed bleeding would probably be preferential. Moreover, prophylactic endoscopic coagulation of the exposed vessels in the mucosal defect of EMR does not seem to prevent delayed bleeding [29].

Perforation rates during endoscopic resection are reported to be $0.05 \%, 0.58-0.8 \%$, and $2-14 \%$ for polypectomy, EMR, and ESD, respectively [20]. In hemodynamically stable, nonimmunosuppressed patients with adequately prepared bowel and no signs of generalized peritonitis, use of endoscopic clips and antibiotic administration has been reported as a favorable treatment of iatrogenic colonic perforations, with success rates ranging between $81.3 \%$ and $100 \%$ [30,31]. Overthe-scope clipping devices have shown good results, with up to $90 \%$ successful closure of perforations, although larger studies are needed to fully assess the efficacy and safety of these devices [32].

\section{Long-term curative rates and surgical intervention}

Overall surgical intervention is required after an attempted EMR in 8.3-13.5\% of cases. Possible reasons are: adverse histopathology, i.e. invasive cancer following a successful EMR (3.7-4.8\% of cases); 2) initial non-curative resection for various conditions, such as submucosal fibrosis, non-lifting sign and difficult positioning (2.3-8.8\%); or 3) complications encountered (0.5\%), such as perforation or intractable bleeding [2,9]. An important finding is that surgical referral for recurrences non-amenable to endoscopic resection after initial successful EMR is needed in only $0.2-1 \%$ of cases [3].

\section{Modified EMR techniques}

\section{EMR-precutting (EMR-P)}

EMR-P is a technique that combines ESD tools with EMR to remove larger tumors that would be difficult to snare en bloc with classic EMR. After the submucosal fluid injection, the mucosa is incised 5-10 mm away from the tumor with a flex knife. A $35-\mathrm{mm}$ oval snare is then applied round the tumor at the mucosal incision site. The mucosal incision enables effective snaring without slippage of the snare.

A retrospective study that compared EMR, EMR-P and ESD for the treatment of large colorectal tumors [32] demonstrated that lesions removed by EMR and EMR-P were of similar size, whereas EMR-P compared to EMR had a significantly higher en bloc resection rate (65.2\% vs. $42.9 \%)$ and complete resection rate $(59.4 \%$ vs. $32.9 \%)$. The recurrence rate was $25 \%$ vs. $3 \%$, respectively. In $90 \%$ of the recurrences the EMR had piecemeal resection. All the recurrences in the EMR group, apart from one patient who needed surgery, were successfully treated with one additional EMR. Interestingly, 15.7\% of EMR, 29\% of EMR-P and $37.9 \%$ of ESD cases were adenocarcinomas. Of the patients with adenocarcinoma treated with EMR, $9 \%$ underwent surgery because of uncertain margins in the histopathology, compared with $0 \%$ of those treated with EMR-P. In terms of complications, perforation rates were not significantly different, though slightly higher for EMR-P (2.9\% compared to none in the EMR group).

EMR-P with a certain degree of additional submucosal dissection before snaring the lesion is the definition of hybrid/simplified ESD, or knife-assisted EMR. The complication rate for hybrid ESD seems to be similar to that of ESD and further studies are needed to establish the indications for this procedure [33]. In a recent prospective study [34], knife-assisted EMR was used to remove polyps that could not be lifted because of scar tissue. In this study, ESD was performed for approximately $10 \mathrm{~mm}$ around the polyp into the scar tissue before the lesion was snared. The success in polyp eradication was $90 \%$, with no perforations, but there was a delayed bleeding rate of $5 \%$.

Overall, it was highlighted that the technique can be useful in cases where carcinoma is suspected and, in the absence of ESD, en bloc resection is required to prevent unnecessary operation on the basis of uncertain histopathological margins. EMR-P seems to offer an intermediate method for the endoscopist who is not experienced in ESD. In the correct hands, it has good technical success rates with the advantages of a low recurrence rate and higher en bloc resection. Randomized controlled headto-head studies are needed, as it may carry higher complication rates than traditional EMR.

\section{Underwater EMR}

This novel EMR technique was first described in 2012 [35], when polyps larger than $2 \mathrm{~cm}$ were snared without prior submucosal injection. Instead, the lumen was initially deflated and the polyp was totally immersed in water using a water pump. 
The theory behind the technique was based on an observation made during colonic endoscopic ultrasound, where it was noticed that, when the lumen is filled with water, the colonic muscularis propria remains circular and the water floats the mucosa and submucosa away from the deeper muscular layer, creating a safety cushion. Few single-center prospective studies have given good results [36]. A recent study with the largest series of 81 polyps treated with underwater EMR demonstrated en bloc resection in two thirds of the cases. Successful EMR with no macroscopic residual tissue was demonstrated in all cases [37] and no recurrence was seen at 3-month follow up.

In another recent prospective study, lesions between 2 and $4 \mathrm{~cm}$ were removed en bloc with a $33-\mathrm{mm}$ snare. The study design was based on the observation that water immersion results in less distension of the bowel lumen, contraction of the adenomatous tissue, and reduction of the haustral folds, enabling the snare to capture a larger mucosal surface even in lesions straddling a fold. In 55\% of cases, complete en bloc resections was achieved and no recurrence was seen in these cases. In those that needed piecemeal resection, the recurrence rate was $5 \%$ at $4-6$-month follow up [38].

Almost 200 underwater EMRs have been performed in a few prospective studies to date. Interestingly, no perforation has been reported. The main complication is delayed bleeding in $0.5-5 \%$, with no need of transfusion or intervention [39]. Intraprocedural bleeding was rare and minor and usually ceased spontaneously. Interestingly, this study confirms a previous report where the use of heated water at $37^{\circ} \mathrm{C}$ to fill the lumen reduced bowel peristalsis [40].

The underwater EMR technique appears to be a promising method of EMR, given the significantly low rates of adverse events reported, the reduction in procedure time, the possible cost-effectiveness and the short learning curve [39]. In addition, there is a possibility that larger lesions can be removed en bloc, leading to negligible recurrence rates. The disadvantages of the technique are the need for good bowel preparation and the poor views when there is vigorous bleeding. Large multicenter studies are needed to determine the efficacy and complications of the technique.

\section{Cap-assisted EMR (C-EMR)}

C-EMR is a modified technique in which a transparent plastic mucosectomy cap is mounted on the tip of the colonoscope. At its distal end, the cap has a gutter that positions the open polypectomy snare. The polyp is lifted with submucosal fluid injection and the cap is placed against the polyp. Mild suction is applied to make the polyp fill half of the cap. The snare is closed round the aspirated mucosa and the lesion is resected.

C-EMR has been used for EMRs in the upper gastrointestinal tract, mainly the stomach and esophagus; however, the use of this method in the colon is not popular, given the possible entrapment of muscularis propria in the cap with consequent perforation. In the largest study to date, 255 cases of C-EMR performed in lesions larger than $2 \mathrm{~cm}$ were evaluated [41]. The median diameter of the resected specimens was $13 \mathrm{~mm}$ (range
12-16). All polyps were removed piecemeal. The median size of the LSTs was $30 \mathrm{~mm}$ (range 20-100) and of the sessile polyps $25 \mathrm{~mm}$ (range 20-80). APC was used for residual tissues in $22.3 \%$ of the cases. The recurrence rate after a median period of 12.1 (5.5-71.2) months was $4 \%$ and the recurrent polyps were treated endoscopically with APC or EMR in one session.

Intraprocedural bleeding occurred in $7.4 \%$ and was managed endoscopically. No delayed bleeding and no perforations occurred. Conio et al highlighted the need for controlled suction to prevent perforation and commented that in many cases suction is not necessary, as pressure against the lesion causes its protrusion into the cap.

The advantages of C-EMR were confirmed in a recent retrospective study that included 124 polyps [42], 60\% of which were larger than $2 \mathrm{~cm}$. The decision to use C-EMR was made case by case, as it is considered the best method for flat polyps in difficult locations. Of the polyps included, $45 \%$ were flat polyps, $14 \%$ were polyps involving the ileocecal valve (ICV), and $5 \%$ were polyps involving the appendiceal orifice.

During a median follow up of 4.2 months (range 1.646.8 months), the recurrence rate after a successful C-EMR was $1.2 \%$, while for all attempted C-EMRs polyp removal was successful in $91 \%$. The reasons for failure were an inadequate grasp of the polyp (scarring/carcinoma) and difficult position and/or size.

The perforation rate was $3.9 \%$, of which 2 cases needed surgery and the rest were managed endoscopically with endoclips. Perforation rates in previous studies with small numbers of patients were $2.5-4 \%$. There was $3.9 \%$ intraprocedural bleeding and $2.4 \%$ delayed bleeding managed endoscopically.

The cap seems to offer better visualization of the operative field and the possibility of resecting lesions located in difficult places. The cap is advantageous in interhaustral lesions and lesions involving the ICV, as the exposure of the lesion is greater, helping keep the ileum distended and facilitating the placement of the snare.

Despite the fact that C-EMR was used as a technique for piecemeal EMR in all the above studies, the recurrence rate is low, probably because of the improved visualization of the field and the suction of normal mucosa along with the lesions at the margins of the lesion. The technique needs adequate training, as it has shown increased perforation rates in non-experienced hands. Most of the perforations occurred in the first quarter of the period included in the study as the endoscopist gained experience [41].

\section{Endoscopic submucosal resection with band ligation (ESMR-L)}

This modified EMR technique has been used to remove small rectal neuroendocrine tumors. A multi-band ligation device is mounted on the colonoscope. Submucosal saline solution is injected beneath the tumor to reduce the risk of perforation. The lesion is then aspirated into the ligation device and an elastic band is deployed. The snared lesion is then resected below the band. 
Carcinoid tumors less than $1 \mathrm{~cm}$ in the rectum have a low risk of metastatic disease and local treatment is considered curative. As the carcinoid extends to the submucosa, resection techniques must aim for complete resection. The use of a ligation device in the esophagus has shown a maximum thickness of submucosa resected up to $1200 \mu \mathrm{m}$ (median $800 \mu \mathrm{m}$, range 500-1200) [43].

The efficacy of ESMR-L in resecting small rectal carcinoids has been compared to that of standard EMR and ESD. Complete resection with histopathologically negative margins has been reported in $94.3-100 \%$ of ESMR-L vs. $75.7-80 \%$ of EMR cases $[44,45]$. ESMR-L has shown equivalent complete resection rates to those of ESD ( $100 \%$ vs. $92 \%$, respectively), while offering the advantages of a shorter procedural duration and shorter (if any) hospital admission [46].

No perforations occurred in all the above studies. The results of a recent meta-analysis confirm that treatment of rectal carcinoid tumors with ESD or ESMR-L is superior to EMR, and that the efficacy of ESMR-L is equivalent to ESD treatment [47].

\section{Concluding remarks}

Classic EMR, especially in tertiary centers, can successfully remove more than $90 \%$ of the polyps. Any variation of the technique should aim to resolve specific problems where classic EMR is not successful, such as submucosal fibrosis, polyps in difficult locations, or superficial submucosal invasion. The variations discussed are promising, but large studies are needed before they can be widely adopted.

\section{Acknowledgment}

The images of the EMR cases, were kindly supplied by Professor Paul O'Toole, Consultant Endoscopist and Gastroenterologist at Royal Liverpool University Hospital.

\section{References}

1. Rilley S. Colonoscopic polypectomy and endoscopic mucosal resection: a practical guide. British Society of Gastroenterology Guidelines, 2008.

2. Hassan C, Repici A, Sharma P, et al. Efficacy and safety of endoscopic resection of large colorectal polyps: a systematic review and meta-analysis. Gut 2016;65:806-820.

3. Belderbos TD, Leenders M, Moons LM, Siersema PD. Local recurrence after endoscopic mucosal resection of nonpedunculated colorectal lesions: systematic review and meta-analysis. Endoscopy 2014;46:388-402.

4. Fukami N, Lee JH. Endoscopic treatment of large sessile and flat colorectal lesions. Curr Opin Gastroenterol 2006;22:54-59.

5. Tanaka S, Kashida H, et al. JGES guidelines for colorectal endoscopicc submucosal dissection/endoscopicmucosal resection. Dig Endosc 2015;27:417-434.
6. Saito Y, Yamada M, So E, et al. Colorectal endoscopic submucosal dissection: Technical advantages compared to endoscopic mucosal resection and minimally invasive surgery. Dig Endosc 2014;26 Suppl 1:52-61.

7. Ikematsu $\mathrm{H}$, Yoda $\mathrm{Y}$, Matsuda $\mathrm{T}$, et al. Long-term outcomes after resection for submucosal invasive colorectal cancers. Gastroenterology 2013;144:551-559; quiz e14.

8. Moss A, Bourke MJ, Williams SJ, et al. Endoscopic mucosal resection outcomes and prediction of submucosal cancer from advanced colonic mucosal neoplasia. Gastroenterology 2011;140:1909-1918.

9. Moss A, Williams SJ, Hourigan LF, et al. Long-term adenoma recurrence following wide-field endoscopic mucosal resection (WF-EMR) for advanced colonic mucosal neoplasia is infrequent: results and risk factors in 1000 cases from the Australian Colonic EMR (ACE) study. Gut 2015;64:57-65.

10. Hotta K, Fujii T, Saito Y, Matsuda T. Local recurrence after endoscopic resection of colorectal tumors. Int J Colorectal Dis 2009;24:225-230.

11. Woodward TA, Heckman MG, Cleveland P, De Melo S, Raimondo M, Wallace M. Predictors of complete endoscopic mucosal resection of flat and depressed gastrointestinal neoplasia of the colon. Am J Gastroenterol 2012;107:650-654.

12. Brooker JC, Saunders BP, Shah SG, Thapar CJ, Suzuki N, Williams CB. Treatment with argon plasma coagulation reduces recurrence after piecemeal resection of large sessile colonic polyps: a randomized trial and recommendations. Gastrointest Endosc 2002;55:371-375.

13. Zlatanic J, Waye JD, Kim PS, Baiocco PJ, Gleim GW. Large sessile colonic adenomas: use of argon plasma coagulator to supplement piecemeal snare polypectomy. Gastrointest Endosc 1999;49:731-735.

14. Regula J, Wronska E, Polkowski M, et al. Argon plasma coagulation after piecemeal polypectomy of sessile colorectal adenomas: longterm follow-up study. Endoscopy 2003;35:212-218.

15. Raju GS, Lum PJ, Ross WA, et al. Outcome of EMR as an alternative to surgery in patients with complex colon polyps. Gastrointest Endosc 2016;84:315-325.

16. Tsiamoulos ZP, Bourikas LA, Saunders BP. Endoscopic mucosal ablation: a new argon plasma coagulation/injection technique to assist complete resection of recurrent, fibrotic colon polyps (with video). Gastrointest Endosc 2012;75:400-404.

17. Holmes I, Kim HG, Yang DH, Friedland S. Avulsion is superior to argon plasma coagulation for treatment of visible residual neoplasia during EMR of colorectal polyps (with video). Gastrointest Endosc 2016 Apr 11 [Epub ahead of print]. doi: 10.1016/j.gie.2016.03.1512

18. Bassan MS, Cirocco M, Kandel G, et al. A second chance at EMR: the avulsion technique to complete resection within areas of submucosal fibrosis. Gastrointest Endosc 2015;81:757.

19. Veerappan SG, Ormonde D, Yusoff IF, Raftopoulos SC. Hot avulsion: a modification of an existing technique for management of nonlifting areas of a polyp (with video). Gastrointest Endosc 2014;80:884-888.

20. Nakajima T, Saito Y, Tanaka S, et al. Current status of endoscopic resection strategy for large, early colorectal neoplasia in Japan. Surg Endosc 2013;27:3262-3270.

21. Watabe H, Yamaji Y, Okamoto M, et al. Risk assessment for delayed hemorrhagic complication of colonic polypectomy: polyprelated factors and patient-related factors. Gastrointest Endosc 2006;64:73-78.

22. Buchner AM, Guarner-Argente C, Ginsberg GG. Outcomes of EMR of defiant colorectal lesions directed to an endoscopy referral center. Gastrointest Endosc 2012;76:255-263.

23. Burgess NG, Metz AJ, Williams SJ, et al. Risk factors for intraprocedural and clinically significant delayed bleeding after wide-field endoscopic mucosal resection of large colonic lesions. Clin Gastroenterol Hepatol 2014;12:651-661.e1-3.

24. Liaquat H, Rohn E, Rex DK. Prophylactic clip closure reduced 
the risk of delayed postpolypectomy hemorrhage: experience in 277 clipped large sessile or flat colorectal lesions and 247 control lesions. Gastrointest Endosc 2013;77:401-407.

25. Bahin FF, Rasouli KN, Byth K, et al. Prediction of clinically significant bleeding following wide-field endoscopic resection of large sessile and laterally spreading coloractal lesions: a clinical score. Am J Gastroenterol 2016;111:1115-1122.

26. Metz AJ, Bourke MJ, Moss A, Williams SJ, Swan MP, Byth K. Factors that predict bleeding following endoscopic mucosal resection of large colonic lesions. Endoscopy 2011;43:506-511.

27. Burgess NG, Williams SJ, Hourigan LF, et al. A management algorithm based on delayed bleeding after wide-field endoscopic mucosal resection of large colonic lesions. Clin Gastroenterol Hepatol 2014;12:1525-1533.

28. Bahin FF, Naidoo M, Williams SJ, et al. Prophylactic endoscopic coagulation to prevent bleeding after wide-field endoscopic mucosal resection of large sessile colon polyps. Clin Gastroenterol Hepatol 2015;13:724-730.e1-e2.

29. Yoon JY, Kim JH, Lee JY, et al. Clinical outcomes for patients with perforations during endoscopic submucosal dissection of laterally spreading tumors of the colorectum. Surg Endosc 2013;27:487-493.

30. Kim JS, Kim BW, Kim JI, et al. Endoscopic clip closure versus surgery for the treatment of iatrogenic colon perforations developed during diagnostic colonoscopy: a review of 115,285 patients. Surg Endosc 2013;27:501-504.

31. Haito-Chavez Y, Law JK, Kratt T, et al. International multicenter experience with an over-the-scope clipping device for endoscopic management of GI defects (with video). Gastrointest Endosc 2014;80:610-622.

32. Lee EJ, Lee JB, Lee SH, Youk EG. Endoscopic treatment of large colorectal tumors: comparison of endoscopic mucosal resection, endoscopic mucosal resection-precutting, and endoscopic submucosal dissection. Surg Endosc 2012;26:2220-2230.

33. Toyonaga T, Man-I M, Morita Y, Azuma T. Endoscopic submucosal dissection (ESD) versus simplified/hybrid ESD. Gastrointest Endosc Clin N Am 2014;24:191-199.

34. Chedgy FJ, Bhattacharyya R, Kandiah K, Longcroft-Wheaton G, Bhandari P. Knife-assisted snare resection: a novel technique for resection of scarred polyps in the colon. Endoscopy 2016;48:277-280.

35. Binmoeller KF, Weilert F, Shah J, Bhat Y, Kane S. "Underwater" EMR without submucosal injection for large sessile colorectal polyps (with video). Gastrointest Endosc 2012;75:1086-1091.

36. Uedo N, Nemeth A, Johansson GW, Toth E, Thorlacius H. Underwater endoscopic mucosal resection of large colorectal lesions. Endoscopy 2015;47:172-174.

37. Curcio G, Granata A, Ligresti D, et al. Underwater colorectal EMR: remodeling endoscopic mucosal resection. Gastrointest Endosc 2015;81:1238-1242.

38. Binmoeller KF, Hamerski CM, Shah JN, Bhat YM, Kane SD, Garcia-Kennedy R. Attempted underwater en bloc resection for large $(2-4 \mathrm{~cm})$ colorectal laterally spreading tumors (with video). Gastrointest Endosc 2015;81:713-718.

39. Wang AY, Flynn MM, Patrie JT, et al. Underwater endoscopic mucosal resection of colorectal neoplasia is easily learned, efficacious, and safe. Surg Endosc 2014;28:1348-1354.

40. Church JM. Warm water irrigation for dealing with spasm during colonoscopy: simple, inexpensive, and effective. Gastrointest Endosc 2002;56:672-674.

41. Conio M, Blanchi S, Repici A, Ruggeri C, Fisher DA, Filiberti R. Cap-assisted endoscopic mucosal resection for colorectal polyps. Dis Colon Rectum 2010;53:919-927.

42. Kashani A, Lo KS, Jamil LH. Cap-assisted endoscopic mucosal resection is highly effective for nonpedunculated colorectal lesions. J Clin Gastroenterol 2016;50:163-168.

43. Pouw RE, van Vilsteren FG, Peters FP, et al. Randomized trial on endoscopic resection-cap versus multiband mucosectomy for piecemeal endoscopic resection of early Barrett's neoplasia. Gastrointest Endosc 2011;74:35-43.

44. Im YC, Jung SW, Cha HJ, et al. The effectiveness of endoscopic submucosal resection with a ligation device for small rectal carcinoid tumors: focused on previously biopsied tumors. Surg Laparosc Endosc Percutan Tech 2014;24:264-269.

45. Ono A, Fujii T, Saito Y, et al. Endoscopic submucosal resection of rectal carcinoid tumors with a ligation device. Gastrointest Endosc 2003;57:583-587.

46. Niimi K, Goto O, Fujishiro M, et al. Endoscopic mucosal resection with a ligation device or endoscopic submucosal dissection for rectal carcinoid tumors: An analysis of 24 consecutive cases. Dig Endosc 2012;24:443-447.

47. He L, Deng T, Luo H. Efficacy and safety of endoscopic resection therapies for rectal carcinoid tumors: a meta-analysis. Yonsei Med J 2015;56:72-81. 